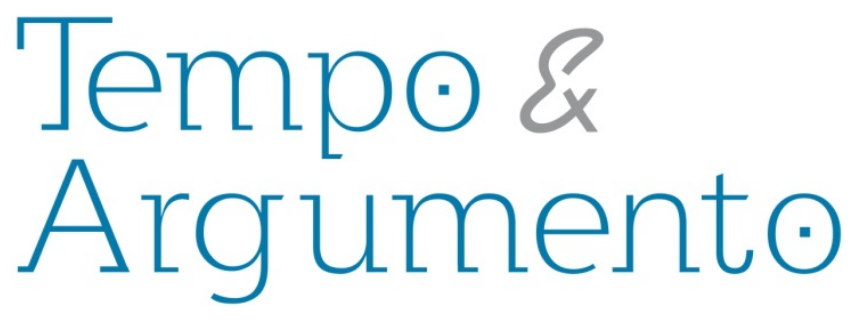

\title{
A recusa do segredo: exercício de direitos e acesso a documentos públicos ${ }^{1}$
}

\begin{abstract}
Resumo
A partir de situações relativamente recentes e polêmicas de disponibilização, na Internet (por meio do WikiLeaks), de grande volume de documentos sigilosos produzidos no âmbito de instâncias governamentais e referentes a diversos países, são discutidos aspectos históricos que envolvem o acesso à documentação arquivística de caráter público, sua utilização para a produção de conhecimento histórico e sua relevância para o exercício da cidadania e a consolidação de práticas democráticas. Aborda-se ainda, brevemente, o debate arquivístico acerca da avaliação de documentos de arquivo e sua relação com o tema do acesso aos arquivos.
\end{abstract}

Palavras-chave: Arquivos públicos. Acesso. Avaliação. Cidadania. História.

\author{
Janice Gonçalves \\ Doutora em História. \\ Professora da Universidade do \\ Estado de Santa Catarina. \\ janice_goncalves@hotmail.com
}

\section{Para citar este artigo:}

GONÇALVES, Janice. A recusa do segredo: exercício de direitos e acesso a documentos públicos.

Revista Tempo e Argumento. Florianópolis, v. 5, n.9, jan./jun. 2013. p. 266 - 287.

\section{DOI: $10.5965 / 2175180305092013266$}

http://dx.doi.org/10.5965/2175180305092013266

\footnotetext{
${ }^{1}$ Versão ampliada e atualizada de texto apresentado na mesa redonda "A prática da confidencialidade e o direito de acesso a documentos produzidos pelo poder público", que integrou a programação do XVI Congresso Brasileiro de Arquivologia - "O lugar do arquivo", realizado em Santos, SP, entre 24 e 27 de agosto de 2010.
} 


\title{
THE REFUSAL OF SECRETS: exercise of rights and access to public archives
}

\begin{abstract}
Thousands of secret government registers relative to many countries were published in recent years at the Internet through WikiLeaks. This polemic action gives the opportunity to discuss, in this article, some historical aspects of the access to public archival documents, their use for the production of historical knowledge and their relevance to citizenship and to consolidate democratic practices. The debate about archival appraisal and its relationship to archival documents access are also briefly discussed.
\end{abstract}

Keywords: Public archives. Access. Appraisal.

Citizenship, history.

No final de julho de 2010, os meios de comunicação deram grande destaque à disponibilização, em sítio eletrônico, de mais de setenta mil documentos sigilosos relativos às ações militares estadunidenses no Afeganistão, referentes aos seis anos anteriores. A leitura do "Diário da Guerra Afegã" - nome atribuído ao conjunto daqueles documentos pelo WikiLeaks, responsável pela sua divulgação - revelava parte 
significativa do cotidiano da guerra, ausente dos noticiários. ${ }^{2}$ Polêmica, a iniciativa gerou críticas do governo dos EUA e de diversas entidades, especialmente em função de os documentos identificarem colaboradores das forças de ocupação no Afeganistão, o que colocaria suas vidas em risco. Por outro lado, foram também expressivas as manifestações favoráveis, saudando a relevância dos meios de comunicação na defesa dos direitos à informação e à liberdade de expressão.

O “Diário da Guerra Afegã” seria sucedido por novas publicações impactantes e polêmicas promovidas pelo WikiLeaks: em outubro de 2010, cerca de 400 mil documentos secretos sobre a ocupação do Iraque pelos EUA e, em novembro, mais de duzentos mil documentos diplomáticos produzidos por embaixadas estadunidenses. A divulgação abalaria os governos envolvidos (sobretudo o dos Estados Unidos), mas o WikiLeaks não sairia incólume: passaria a ter problemas para sustentar financeiramente suas ações (instituições financeiras bloquearam transferências bancárias e doações com cartões de crédito feitas ao WikiLeaks), apoiadores conhecidos sofreriam represálias e seu editorchefe, Julian Assange, seria processado e preso sob acusação de crimes sexuais supostamente realizados na Suécia. Como consequência dos desdobramentos do processo sobre abuso sexual e estupro, Assange esteve em regime de prisão domiciliar, em Londres, entre dezembro de 2010 e maio de 2012, até a confirmação de sua extradição para a Suécia. A extradição, contudo, não foi efetivada em função do pedido de asilo feito por Assange à embaixada do Equador em Londres (ASSANGE, 2013, p.37-41 e 161-163).

O sítio eletrônico WikiLeaks, acessível desde 2006, é a face visível e o principal instrumento de atuação de uma organização cujo objetivo fundamental é disponibilizar informações que, não obstante seu interesse público, foram sistematicamente ocultadas. Para obtê-las e disseminá-las, o WikiLeaks conta com uma rede de pessoas dispostas a realizar denúncias (geralmente jornalistas e ativistas) e, de forma a garantir o anonimato desses colaboradores, mobiliza softwares contendo algoritmos de criptografia (VIANA, 2013, p.12). Conforme o sítio eletrônico do WikiLeaks, todo esse trabalho é feito tendo em

\footnotetext{
O “Diário da Guerra Afegã" foi primeiramente disponibilizado no endereço eletrônico <http://wardiary.wikileaks.org/> e em 2013 pode ser consultado em <http://wikileaks.org/wiki/Afghan_War_Diary,_2004-2010>.
} 
vista três princípios: "a defesa da liberdade de expressão e de imprensa, o aperfeiçoamento de nossos registros históricos em comum e o apoio aos direitos de todos os povos de criar história nova." Além disso, é dada ênfase à divulgação de grande número de documentos que, de maneira contundente, comprovam as denúncias: com isso, de acordo com os responsáveis pelo WikiLeaks, "leitores e também historiadores podem ver a evidência da verdade". ${ }^{3}$

Cabe indagar acerca dos significados dessa "história nova" cujo direito de produzir é afirmado pelo WikiLeaks. Nova, talvez, por ser recente? O viés político de suas ações autoriza a pensar em outra perspectiva de "novidade": narrativas históricas diferentes das hegemônicas, em geral construídas a partir daquilo que passou pelo crivo da censura, foi permitido revelar e tornou-se aberto à consulta pública. Uma "história nova" atravessaria, assim, as malhas da ocultação. O impressionante volume de documentos sigilosos disponibilizados no sítio eletrônico do WikiLeaks, desde sua criação, coloca em xeque, portanto, a documentação efetivamente disponível para consulta em instituições arquivísticas públicas e a possibilidade de construir, a partir dela, uma história que efetivamente ultrapasse os limites impostos por interesses de grupos que controlem tanto instâncias estatais como o acesso aos registros documentais por elas gerados. Mais do que isso: em uma época que valoriza a velocidade e almeja tudo devassar (de preferência, em “tempo real”), é inevitável que a impactante divulgação, a todo e qualquer usuário da Internet, de milhares de documentos, parte significativa deles relativos a ações militares (que, em mais de um sentido, têm sido muito custosas), remeta à morosidade e à opacidade das instituições governamentais, aí englobadas as instituições arquivísticas públicas.

As dúvidas surgem com força: afinal, a quais documentos públicos, de fato, os cidadãos têm acesso? Em circunstâncias nas quais o acesso a documentos públicos de arquivo possa vir a mudar os rumos de uma guerra, alterar uma rede de alianças políticas, reduzir o apoio a um governo ou prejudicar um projeto de dominação, qual a probabilidade da consulta a esses documentos ser permitida e realizada de forma ágil? A

\footnotetext{
${ }^{3}$ Cf.: <http://wikileaks.org/About.html >. Acesso em 13 mai.2013.
} 
legislação reguladora do acesso, bem como as instâncias responsáveis pelo seu cumprimento, seriam suficientes para garantir que a documentação em questão fosse disponibilizada em instituição arquivística pública a qualquer cidadão interessado? Como evitar que a legislação que bloqueia o acesso aos documentos em nome da "segurança nacional" e que ao mesmo tempo busca o tratamento ético das informações concernentes aos indivíduos sirva, pragmaticamente, a interesses políticos menos nobres, mais estreitos e imediatos? Como cumpridoras fiéis dessa legislação, não seriam as instituições arquivísticas também cúmplices da lógica do segredo, mais do que alicerces da transparência das ações governamentais e instrumentos da democracia? Ou ainda, como indagou Cassie Findlay: "agora, como a tecnologia nos permite eliminar muitos dos obstáculos do legado da gestão documental baseada em papel, é possível aos arquivos reivindicar sua posição no coração de uma democracia saudável?" (FINDLAY, 2013, p.7-8).

\section{O que se oculta, o que se mostra?}

Como pensar a relação entre governantes e governados, por meio dos arquivos?

Os documentos governamentais são produzidos em função da interação dos governos com os governados: seja porque os governantes, ou seus prepostos, voltam-se para os governados para identificá-los, captar seus perfis e suas demandas e, no limite, controlá-los, seja porque os governados respondem a essas intervenções e suscitam outras. Em virtude disso, ao lado, por exemplo, de listagens que buscam realizar o censo populacional ou registrar os proprietários dos imóveis de uma dada faixa territorial, podem ser encontrados, nos arquivos governamentais, requerimentos de toda ordem feitos pelos cidadãos às autoridades. Na legislação brasileira, as demandas dos cidadãos foram claramente previstas na maioria dos documentos constitucionais, na forma da garantia de dois direitos: o de petição aos poderes públicos (em defesa de outros direitos ou contra ilegalidades e abusos) ${ }^{4}$ e o de contestação (objetivando anulação de ato

${ }^{4}$ O direito de petição estava previsto nas constituições de 1824 (Art. 179, inciso XXX), 1891 (Art. 72, parágrafo 9), 1934 (Art. 113, parágrafo 10), 1937 (Art. 122, parágrafo 7), 1946 (Art. 141, parágrafo 37), 1967 (Art. 150, parágrafo 31, na redação original, e Art.152, parágrafo 31, com a redação modificada de 1969), 
considerado lesivo ao patrimônio público) $)^{5}$. Uma vez exercidos, os direitos de petição e de contestação produziram (e podem continuar a produzir) documentos que, encaminhados às instâncias públicas competentes, foram (e, contemporaneamente, devem ser) integrados aos seus respectivos conjuntos documentais.

Além disso, a estreita proximidade entre os documentos emanados dos órgãos públicos e a população para a qual eles estão voltados fez com que o acesso às informações dos documentos públicos de arquivo estivesse previsto por lei em momentos históricos muito anteriores ao dos debates modernos em torno da cidadania e do interesse público. O arquivista italiano Elio Lodolini (1993, p.247) destaca, por exemplo, que a solicitação, por particulares, de cópias de documentos com fé pública, para fins jurídicos, "chegou a ser um fato normal”, durante o Império Romano; outros pesquisadores complementam que essas cópias eram obtidas mediante requerimento ao imperador, que as autorizava por escrito (SILVA et al, 1999, p.64). Lodolini (1993, p.247) também ressalta o livre acesso aos arquivos das comunas medievais na Península Itálica.

$\mathrm{Na}$ legislação brasileira, antes que o direito de acesso à informação fosse plenamente reconhecido (como o foi, pela Constituição Federal de 1988, em seu Art. $5^{\circ}$., inciso XIV), o direito de obtenção de certidões de repartições públicas, em defesa da garantia de outros direitos ou para obtenção de esclarecimentos, foi sustentado nos textos constitucionais de 1934 (Art. 113, parágrafo 35), 1946 (Art. 141, parágrafo 36), 1967 (Art. 150, parágrafo 34, e Artigo 153, parágrafo 35 na redação modificada de 1969). ${ }^{6}$ O tipo

1988 (Art. $5^{\circ}$., inciso XXXIV, alínea a). A Constituição de 1824 determinava: "Todo Cidadão poderá apresentar por escrito ao Poder Legislativo e ao Executivo reclamações, queixas, ou petições, e até expor qualquer infração da Constituição, requerendo perante a competente autoridade a efetiva responsabilidade dos infratores." A Constituição de 1937 destacava mais sinteticamente que o direito "de representação ou petição perante as autoridades" estava escorado na defesa "de direitos ou do interesse geral”. (CAMPANHOLE, 1994).

${ }^{5}$ Previsto nas constituições de 1934 (Art. 113, parágrafo 38), 1946 (Art. 141, parágrafo 38), 1967 (Art. 150, parágrafo 31, na redação original, e Art.152, parágrafo 31, com a redação modificada de 1969), 1988 (Art. $5^{\circ}$., inciso LXXIII). Pela Constituição de 1988 podem ser igualmente contestados atos lesivos à moralidade pública, ao meio ambiente e ao patrimônio histórico e cultural. (CAMPANHOLE, 1994).

${ }^{6}$ Esteve ausente da Constituição de 1937. Acrescente-se que a Constituição de 1988 previu o direito de receber, dos órgãos públicos, não só informações que dissessem respeito aos cidadãos, individualmente (informações "de seu interesse particular"), como informações "de interesse coletivo ou geral" (Art. $5^{\circ}$., inciso XXXIII). Por seu turno, o "habeas data" simultaneamente reforçou e ampliou o direito a tomar 
de esclarecimentos solicitados não foi previsto com precisão pelos textos constitucionais - no de 1967, fala-se apenas em "esclarecimentos de situações", sem mais detalhes; no de 1988, tais esclarecimentos aparecem como referidos a situações de interesse pessoal. Em alguns casos, particularmente nos textos constitucionais de 1934 e 1946, foram feitas ressalvas no tocante à salvaguarda do interesse público: na Constituição de 1934, o esclarecimento solicitado deveria estar referido aos "negócios públicos", com exceção dos casos em que o interesse público impusesse "segredo ou reserva"; na de 1946, o esclarecimento deveria ser relativo a "negócios administrativos", a menos que o interesse público impusesse sigilo.

Mesmo que de forma restrita, e ao menos na letra da lei, o direito de obter certidões em alguma medida permitiu (e tem permitido) acesso às informações relativas aos negócios públicos. Trata-se, contudo, de um acesso indireto, que supõe a intermediação do agente governamental que elaborará a certidão. A lógica das relações do Estado com a sociedade civil permite vislumbrar algumas motivações para isso. De um lado, é reconhecida a necessidade de salvaguardar direitos de particulares garantidos por documentos governamentais; são então reconhecidos direitos pontuais, especificamente referentes aos indivíduos que solicitam as certidões. Nestes casos, o acesso (indireto) aos documentos de arquivo não implica o reconhecimento de um direito coletivo à informação. Levando em conta o provável perfil daqueles que demandariam mais habitualmente essas informações de interesse individual, autores como Alberch Fugueras e Cruz Mundet salientaram o caráter elitista do acesso aos arquivos na maior parte de sua história:

Se representássemos em um segmento os aproximadamente 5.500 anos de existência dos documentos escritos, veríamos que, salvo os últimos trinta e cinco anos [em relação a 1999], no melhor dos casos, um pedacinho, todo o segmento estaria referido a uma constante histórica: o acesso aos documentos está reservado às elites no poder. Só com o desaparecimento das instituições do Antigo Regime a partir da Revolução Francesa (1789), seus papéis - já históricos e carentes de interesse para o Estado - começaram a ser postos à disposição dos pesquisadores; contudo, a informação estratégica, a que confere 
privilégios a quem a possui, continuava a estar ao serviço da gestão do poder e vedada aos cidadãos. (ALBERCH/CRUZ, 1999, p.100).

Mas, além de promoverem acesso pontual e restrito aos documentos, as certidões preservam, em princípio, a integridade física dos documentos e, consequentemente, seu valor de prova, protegendo-os de alterações ou danos. Vale a lembrança: os livros de registros gerados em virtude da Lei de Terras de 1850, justamente porque mantiveram seu valor jurídico, costumam ter sua consulta direta vedada aos usuários, a fim de evitar adulterações. No Arquivo Público do Estado de São Paulo, até a década de 1980, o acesso aos registros de terra era feito por meio de certidões. Em função das dificuldades aí geradas para a pesquisa histórica, foi concebido, nos anos 1980, o projeto de inventário analítico de tais registros, de modo a disponibilizar de forma ampla e sistemática as informações de interesse para os pesquisadores, sem eliminar o impedimento da consulta direta (TESSITORE, 1986, p.188-189). Claro está que a solução encontrada para ampliar o acesso, por meio de uma ferramenta de descrição (inventário analítico), foi proposta em momento no qual as possibilidades de reprodução técnica da documentação estavam sensivelmente mais distantes do cotidiano das instituições arquivísticas brasileiras. $\mathrm{O}$ que se pretende reter, porém, com o exemplo dado, é a preocupação que a instituição custodiadora dos documentos de arquivo usualmente sustenta em relação ao acesso direto aos documentos, que em graus variados sempre resulta em danos à conservação física.

A certidão, portanto, ao fornecer dados pertinentes ao conteúdo dos documentos, aproxima os cidadãos das informações, embora de forma limitada, ao mesmo tempo que os distancia da documentação. Esse jogo de aproximação e distanciamento está presente de distintas maneiras, em diferentes momentos históricos e sociedades, perpassando as relações entre governantes e governados, sempre tensionadas, de parte a parte, por prerrogativas e obrigações, direitos e deveres. Em função disso, os documentos de arquivo puderam servir (e ainda podem), para os governantes, para sustentar a suspeita, a vigilância, a repressão, a opressão. Por consequência, os arquivos puderam (e podem) ser tanto cobiçados (por quem exerce a dominação ou a almeja) como odiados (por quem sofre os efeitos da dominação). 
Historicamente, governantes e governados tanto lutaram para controlar e preservar documentos de arquivo como se empenharam em realizar sua eliminação. Guerras e revoluções são momentos particularmente significativos para apropriações planejadas e destruições interessadas. Os arquivistas espanhóis Alberch Fugueras e Cruz Mundet destacaram a concentração, em Salamanca, de arquivos retirados de áreas republicanas ocupadas pelas tropas comandadas por Franco, durante a Guerra Civil Espanhola, tendo sido os documentos posteriormente utilizados para as ações repressivas do regime franquista; os mesmos autores indicam a destruição de dez quilômetros de documentos do Arquivo Central de Documentos Antigos de Varsóvia pelo exército da Alemanha durante a Segunda Guerra, bem como a destruição de arquivos, bibliotecas e museus promovida pelo exército sérvio em cidades croatas e bósnias (ALBERCH/CRUZ, 1999, p.97-98). Bruno Delmas (2006, p.20) registrou a preocupação especial, na guerra entre sérvios e croatas nos anos 1990, de destruir arquivos cartoriais, de forma a impedir ou dificultar a prova da identidade civil e a reivindicação de direitos, o que também aconteceu na Guerra do Líbano de 1975. De modo similar, na França revolucionária do século XVIII documentos que atestavam direitos de nobres e ordens eclesiásticas foram sistematicamente eliminados.

Nas sociedades ocidentais, a partir do momento em que a relação entre governados e governantes passou a ser atravessada pelas noções de bem comum, cidadania e interesse público - portanto, sobretudo a partir do final do século XVIII -, houve gradual valorização discursiva dos arquivos e uma defesa do acesso a eles como direito coletivo. Entretanto, a garantia de acesso aos arquivos só será significativamente afirmada, em vários países, no pós-1945, uma vez que o reconhecimento do direito à informação como direito fundamental foi consagrado pela Declaração Universal dos Direitos do Homem, de 1948. $\mathrm{O}$ “direito à informação governamental” foi assegurado em vários países a partir de então: em 1951, na Finlândia; em 1966, nos Estados Unidos; em 1970, na Dinamarca e Noruega; em 1978, na França, Holanda e Espanha; em 1982, na

\footnotetext{
7 Cabe ressaltar que, antes mesmo da França, a Suécia, no bojo de preocupações com a liberdade de imprensa, teria garantido, em 1766, livre acesso aos documentos oficiais a todo cidadão sueco.
} 
Austrália, Nova Zelândia e Canadá; em 1985, na Colômbia; em 1993, na Hungria (DUCHEIN, 1983, p.11; JARDIM, 1999, p.70-71).

O direito à informação, a ser exercido pelo conjunto dos cidadãos, teria como contrapartida a necessária prestação de contas à sociedade, da parte dos governos, sem ocultação de procedimentos ou resultados de ações. Mas, em um cenário de implantação de uma nova ordem mundial, marcado pela bipolarização entre EUA e União Soviética e pela chamada "Guerra Fria", é possível vislumbrar a difícil convivência entre o direito à informação e os serviços de espionagem ou contraespionagem, e, consequentemente, a prevalência de uma lógica do segredo em nome da segurança dos Estados nacionais.

\section{Documentos para a História}

É certo que a afirmação ou a defesa de um direito não significa o seu exercício sem entraves, que está sujeito a inúmeras injunções políticas e disputas entre grupos sociais. Por isso a importância de pensar, juntamente com o ordenamento jurídico, os agentes sociais interessados tanto na abertura dos arquivos públicos aos cidadãos como na manutenção de sua interdição. Cabe aqui uma breve menção aos historiadores.

O acesso pontual e restrito a documentos públicos, como aquele feito por meio de certidões ou cópias (sobretudo daqueles documentos com valor probatório de direitos individuais), não poderia satisfazer adequadamente as demandas da pesquisa histórica. Não, ao menos, a partir do século XIX, momento em que a História se constituiu como campo disciplinar e profissional.

Não foram os historiadores do século XIX, certamente, aqueles que primeiro estabeleceram o elo entre pesquisa histórica e arquivos. A utilização dos documentos de arquivo como suporte da investigação de caráter histórico (não somente os governamentais, mas também os privados, em especial os eclesiásticos e familiares) foi possível àqueles que deles tinham proximidade, em função de laços profissionais ou ocupacionais ou de relações pessoais. Entre os antigos, porém - em especial, entre os gregos -, a valorização da história contemporânea, vivida e testemunhada pelo escritor, não encontrou correspondência na valorização à consulta dos arquivos ou à clara 
identificação, por parte dos historiadores, dos documentos eventualmente analisados. Como apontou Paul Veyne (1987, p.19), os autores antigos eram, propriamente, autoridades sobre o passado, e seus relatos formavam a "tradição": o que havia sido escrito era assumido como verdade a ser eventualmente complementada ou corrigida, o que fazia da "verdade histórica" uma "vulgata consagrada pela concordância dos espíritos ao longo dos séculos". Se a investigação acontecera no presente e com testemunhos colhidos diretamente (ou seja, a partir do que o investigador vira ou ouvira), desnecessárias eram as citações das fontes - ainda segundo Veyne (1987, p.20-21), “um historiador antigo [...] é ele próprio fonte e documento".

Também antes do século XIX, a preocupação com a veracidade e autenticidade das fontes pode igualmente ser detectada. Na Europa, investimentos neste sentido são conhecidos ao menos desde o século XII; todavia, no período medieval, mesmo os documentos diplomáticos sofrem alterações (emendas, supressões) com a intenção de facilitar o entendimento ou compatibilizá-los com o que é afirmado "por alguma autoridade ou pela tradição" (CAIRE-JABINET, 2003, p.29-30). Há, porém, grosso modo, uma convergência de interpretações no sentido de situar entre os modernos a transição para um novo modelo de escrita histórica, relacionado ao interesse acentuado em estabelecer procedimentos para detectar documentos autênticos e verificar seu conteúdo de verdade. Mais amplamente, François Hartog entende haver um "regime moderno de historicidade", instalado "entre o final do século XVIII e o início do século XIX", que representa uma ruptura em relação à "história mestra da vida" dos antigos: no regime moderno, a história, compreendida como processo, busca, mais que exemplos, singularidades, sendo o futuro a sua dimensão mais determinante, por dar sentido ao passado - HARTOG, 1997, p. 8-11). Para a construção dessa história de viés moderno houve a contribuição de eruditos (cujos trabalhos forneceriam as bases da "crítica documental"), bem como a influência dos processos argumentativos desenvolvidos nas controvérsias teológicas e no âmbito jurídico, além dos procedimentos oriundos das práticas de antiquariato, tal como salientado por diversos autores (BLOCH, 2002, p.91; CAIRE-JABINET, 2003, p.59, 64, 74-76; GINZBURG, 2002a, p.71-76; GINZBURG, 2002b, p. 155-156; LE GOFF, 1996, p. 537; VEYNE, 1987, p.23-24). 
No século XIX, a incorporação do método de crítica dos documentos ao interesse de construção de uma história científica, contrapondo-se às filosofias da história, articulou-se à defesa da pesquisa empírica, do levantamento sistemático de documentos e de sua análise acurada (CAIRE-JABINET, 2003, p.93-109; CARBONELL, 1986, p.104-125; REIS, 1999, p.11-16). No que se refere aos documentos, esse projeto valorizou particularmente a documentação arquivística pública, não só porque atendia mais favoravelmente às intenções de construção das histórias nacionais ou "histórias pátrias" (confundindo-se, portanto, com a história dos Estados nacionais) como em decorrência das características próprias a essa documentação, que apresentava com clareza os sinais de sua autenticidade e, portanto, emprestava maior confiabilidade ao seu uso e maior solidez aos projetos de história científica então vigentes (CAMARGO, 2009, p.433). Assim, foi especialmente a partir do século XIX que os historiadores passaram a ter papel gradativamente relevante na ampliação do acesso aos documentos arquivísticos públicos: salas de consulta passariam a ser instaladas, nas instituições arquivísticas europeias, em meados do século XIX (SILVA et al., 1999, p.102). Elio Lodolini (1993, p.250-251) cita, a este respeito, os casos do Arquivo Nacional francês e dos arquivos da Alemanha, mas destaca que a liberação da consulta para a pesquisa histórica era então mais exceção do que norma. Pesquisas sobre os inícios da atividade acadêmica em História, na Europa, indicam que o ambiente alemão, entre 1856 e 1915, aproximava doutorandos e seus professores das "sociedades de exploradores, aventurando-se em arquivos espalhados pelos quatro cantos, descobrindo seu conteúdo e voltando para relatar a seus pares o que tinham descoberto." (LAMBERT et al, 2011, p.47). A agitação em torno da história também foi intensa na Grã-Bretanha, onde cedo surgiram as salas de consulta (a primeira seria de 1858) e onde proliferaram as sociedades de estudos históricos (LAMBERT et al., 2011, p.48).

A atuação dos historiadores foi fundamental para vincular os arquivos de caráter permanente e as instituições arquivísticas públicas responsáveis por sua guarda (dotadas de salas de consulta, horários de atendimento e instrumentos de pesquisa) à pesquisa histórica, que durante o século XIX e até meados do século XX foi entendida fundamentalmente como uma pesquisa voltada, em cada país, para a história da nação 
(sendo a história "universal" a história das várias nações). Disseminada, essa visão fixaria, no senso comum, a associação entre os arquivos públicos e seu "valor histórico", tendendo a apagar outros valores neles contempláveis, em especial sua função de base da prestação de contas que os governos devem realizar para os cidadãos.

No século $X X$, sobretudo em seu último quartel, foram tecidas críticas contundentes a uma historiografia forjada na construção de histórias da nação; críticas às suas pretensões de cientificidade “objetiva" e, inevitavelmente, críticas ao privilegiamento dos documentos arquivísticos públicos como base do conhecimento histórico. Esse momento de crítica e de crise apontou, entre outras necessidades, para a de diversificar as fontes nas quais deveria se apoiar a produção de caráter histórico. Em visões reducionistas, investigações históricas baseadas em documentação governamental foram associadas a "histórias oficiais"; contrapor-se a uma história oficial obrigaria, assim, a distanciar-se dos documentos públicos. Em paralelo, assiste-se, nas décadas finais do século XX, à emergência de uma “obsessão pela memória", não apenas no campo historiográfico, mas disseminada socialmente, trazendo, entre suas consequências, a valorização de sujeitos pouco presentes nas narrativas históricas, bem como a valorização dos documentos e testemunhos a eles associados. Se os arquivos públicos tinham sido colocados sob suspeita pelos pesquisadores profissionais, são tomados de assalto por pesquisadores amadores ansiosos por buscar respostas acerca de suas trajetórias familiares (ROUSSO, 1996, p.85-91; HARTOG, 2013, p.151-153).

A “onda memorial”, com suas correspondentes preocupações com o "dever de memória" (quase sempre associadas aos acertos de contas pendentes em relação a eventos traumáticos do século $\mathrm{XX}$ ), também atingiu o campo arquivístico, provocando reflexões acerca dos seus fundamentos teóricos e metodológicos, do papel dos profissionais de arquivo e das instituições arquivísticas (ver, por exemplo: COOK, 1998; SCHWARTZ/COOK, 2004). A reflexão acerca dos significados e dos procedimentos que deveriam envolver a avaliação arquivística é um dos aspectos mais instigantes desse debate.

Ao menos desde meados do século XIX procedeu-se a questionamentos sobre o tema da avaliação arquivística. O foco das preocupações era, então, a questão dos 
espaços ocupados pelas expressivas massas documentais governamentais (e seus consequentes custos de manutenção). Tornava-se necessário definir o que preservar e o que eliminar. E, com base em balanço a este respeito feito por Carol Couture (1996-1997, p.3-31), pode-se afirmar que, até a primeira metade do século XX, a avaliação, grosso modo, ora se debruçou sobre a lógica de produção dos documentos do organismo gerador, ora enfatizou as demandas dos usuários externos aos organismos. Mas, na segunda metade do século $X X$, novos elementos foram acrescentados ao debate; a relação da avaliação com a percepção da história contemporânea e com as perspectivas de construção do conhecimento histórico tiveram peso significativo nessa discussão, particularmente intensa entre os arquivistas da América do Norte, com os proponentes da "estratégia de documentação" (EUA) ou da "macroavalição" (Canadá).

Um dos pontos marcantes e polêmicos que ressalta desse debate arquivístico é a consideração de que a documentação governamental, por mais volumosa e relevante que seja, não é suficiente no trabalho de avaliação realizado pela instituição arquivística pública. Tanto na perspectiva da chamada "estratégia de documentação", proposta por arquivistas estadunidenses nos anos 1980, quanto na da "macroavaliação" canadense, a avaliação não deveria se preocupar em identificar o que seria significativo na documentação de uma dada administração pública, mas sim detectar o que seria relevante para a sociedade na qual estaria inserida essa mesma administração. De acordo com a concepção da "estratégia de documentação", a avaliação não deveria partir dos documentos já existentes na instituição, mas de uma problematização acerca daquilo a ser documentado (SAMUELS, 1986, p.114-121). O arquivista canadense Terry Cook, ao comentar a experiência da macroavaliação, salientou que ela não partiria da análise dos documentos, mas das funções ou competências gerais das instituições que os produziram. Tais funções institucionais seriam tomadas como espécies de "filtros de tendências sociais, atividades, necessidades e desejos, de coisas e conceitos que a sociedade “valoriza”'. (COOK, 1999, p.8-9). Neste sentido, a avaliação dos documentos públicos, além de pautada por critérios externos a ela, deveria ser complementada pela avaliação e incorporação, ao acervo da instituição arquivística responsável pela guarda, 
de documentos de arquivos de outras procedências, bem como de coleções com as mais variadas características, desde que atendessem aos critérios adotados. ${ }^{8}$

Sem aprofundar aqui a apresentação de tais propostas ou problematizar mais profundamente a questão da avaliação arquivística, algo que procurei realizar em outro trabalho (GONÇALVES, 2005, esp. p.84-92), limito-me aqui apenas a apontar que, se a "estratégia de documentação" e a "macroavaliação" têm a qualidade de por em questão a relação dos arquivos com a dimensão da memória social e da construção da história, apresentam a desvantagem de tornar ainda mais intrincadas atribuições já por si bastante amplas e complexas, como as das instituições arquivísticas frente à avaliação de documentos. Também tendem a aproximar o acervo institucional aos centros de documentação (ou seria melhor dizer "centros de memória"?). Afastam-se, assim, do perfil concreto do conjunto arquivístico de referência para sair em busca do “historicamente representativo" sobre e para a sociedade (algo certamente muito difícil de caracterizar e sujeito a uma infinidade de contestações, pois fundamentado em interpretação que se afasta das especificidades do conjunto arquivístico - a respeito, ver CAMARGO, 2003, esp. p.14-15). Abrem-se, ainda, à “instrumentalização política” do trabalho arquivístico, como apontou Angelika Menne-Haritz (MENNE-HARITZ, 1994, p.535). Além disso, tais propostas tendem a pôr de lado a dimensão da sociedade que está presente na própria documentação arquivística pública (dimensão esta produzida nas interações entre cidadãos e governos, como anteriormente discutido) e a valorizar pouco a articulação entre documentos públicos e a necessária prestação de contas dos governantes.

É crescente a demanda por transparência quanto às ações dos governos, algo demonstrado pelo recurso cada vez mais ampliado às ferramentas de governo eletrônico, em diversos países, e de forma espetacular, fora das instâncias governamentais, pelo WikiLeaks. No âmbito do governo federal brasileiro, a preocupação com a transparência

\footnotetext{
${ }^{8}$ Cabe salientar que a discussão canadense valoriza debate anterior, iniciado pelo arquivista Hans Booms, na Alemanha Ocidental, durante a década de 1970. A tradução do texto original de Booms para o inglês é de 1987 e foi veiculada pela revista Archivaria; a tradução para o francês foi publicada na revista Archives de 2001-2002 (BOOMS, 2001-2002, p.7-44). A revista Archives também publicou outro texto de Booms sobre avaliação, em 2003-2004 (BOOMS, 2003-2004, p.19-28).
} 
está mais diretamente voltada para a fiscalização da aplicação de recursos públicos, tal como pode ser verificado no sítio eletrônico "Portal da Transparência do Governo Federal" - <http://www.portaltransparencia.gov.br>. Essa preocupação tem se multiplicado em governos estaduais e municipais, com a criação de sítios eletrônicos similares, sobretudo após a aprovação da Lei federal n. 12.527/2011. No âmbito da sociedade civil, há também iniciativas importantes, como a da associação "Transparência Brasil”, que objetiva combater a corrupção, acompanhando principalmente a realização de licitações, o financiamento das campanhas eleitorais e a atuação de parlamentares e ministros do Supremo Tribunal Federal: <http://www.transparencia.org.br>. Mas é preciso frisar que os documentos de arquivo governamentais, gerados em papel ou em meio eletrônico, são a base dessa transparência, como também tem demonstrado o WikiLeaks.

\section{Considerações finais}

Como considerações finais, caberia ainda ressaltar duas questões: como evitar que documentos de interesse público sejam sonegados aos cidadãos (sonegação essa feita inclusive à revelia da lei e da própria atuação das instituições arquivísticas)? Podem e devem as instituições arquivísticas evitar essa sonegação, inclusive sendo mais ágeis na disponibilização dos documentos sob sua guarda?

A garantia de acesso aos documentos públicos está atrelada a dispositivos legais, mas também às condições de organização e conservação física dos documentos. Quanto à organização e à conservação física, cabe às instituições, tendo em vista as demandas sociais por transparência, o direito à informação e o direito à memória, dispor de recursos humanos e tecnológicos para evitar que o tratamento técnico adequado a ser dado aos documentos impeça o acesso rápido e amplo à documentação. Já a legislação que diz respeito ao acesso, e em especial a que dispõe sobre o que deve ser sigiloso ou não, e por quanto tempo, deve ser cumprida pelas instituições arquivísticas. Se julgada inadequada, convém contestá-la e tentar modificá-la, o que certamente deve envolver a conjugação de muitos esforços, não exclusivos das instituições arquivísticas e nem mesmo da área 
arquivística, pois trata-se de uma questão que envolve os interesses do conjunto de cidadãos. Isso pode ser observado muito claramente no caso brasileiro, consideradas os muitos avanços e recuos em relação a essa questão (WEICHERT, 2009, p.412-422), ao menos desde a Lei federal n.8.159/1991 e até a recente Lei federal n. 12.527/2011, a "Lei de Acesso a Informações".

É, contudo, impossível garantir convenientemente acesso a algo que não se controla, não se conserva, não se conhece, não se compreende: o adequado tratamento técnico dos conjuntos documentais arquivísticos é condição fundamental de sua acessibilidade. Daí a extrema relevância da gestão documental; daí, particularmente, a importância dos procedimentos de classificação e avaliação documental, todos supondo sua realização por pessoal preparado para tarefas tão complexas (o que remete, inevitavelmente, à sua qualificação e ao problema da formação dos profissionais de arquivo). E, se o acesso não deve ser, em princípio, desvinculado da gestão documental, vê-se que é necessário buscar garantias legais e administrativas para que ambos sejam de fato indissociáveis, dotando as instituições arquivísticas dos meios necessários para dar cumprimento às suas atribuições. Garantir o acesso aos documentos públicos de arquivo envolve, consequentemente, fortalecer as instituições arquivísticas públicas: seu papel social deve se tornar mais claro e mais visível, ao mesmo tempo que elas necessitam ser percebidas socialmente como relevantes e confiáveis (e obviamente fazer jus a essa percepção).

Neste sentido, mesmo que a legislação impeça a consulta imediata de documentos classificados como sigilosos, cabe perguntar: a existência destes documentos também deve ser sigilosa? Se a consulta a uma dada documentação estiver temporariamente vedada, em função de direitos individuais à proteção da imagem, da dignidade e da honra, será conveniente silenciar sobre ela? Sonia Combe (1994, p.43-47), referindo-se aos arquivos franceses, demonstrou como o silenciamento em relação ao que está temporariamente indisponível para consulta, resultando em inventários lacunares, é nocivo para os pesquisadores ou interessados em geral na consulta à documentação arquivística, demonstrando um compromisso maior dos arquivistas franceses com a lógica do segredo de Estado do que com a da "prestação de contas" à sociedade. O 
mergulho de Sonia Combe no mundo dos arquivos franceses fez inclusive com que adquirisse "a convicção de que o modo de gestão dos nossos arquivos [na França] constitui um enclave de 'totalitarismo' no nosso espaço democrático" (COMBE, 1994, p.27). Se decididamente comprometidas com a transparência, portanto, as instituições arquivísticas deveriam apresentar informações gerais sobre tais documentos ainda indisponíveis (quer por não estarem organizados, quer por necessitarem de cuidados de conservação, quer por serem classificados como sigilosos): datas-limite, atividades geradoras, dados gerais neles contidos, tramitação, documentos que a eles se relacionam etc., algo que é necessariamente levantado no processo de avaliação arquivística. Por que, então, não buscar garantir que o controle da documentação produzida, seu trâmite, seus prazos de guarda, sua destinação, sejam amplamente divulgados?

As tecnologias de informação já servem à gestão documental, sendo importante que os sistemas informatizados existentes se preocupem em interagir com os usuários da própria administração pública e com os usuários-cidadãos. É fundamental que os "interessados em geral" estejam no horizonte não apenas dos arquivos públicos em sua fase permanente, mas em todas as suas fases. Como deixa claro o episódio aqui relatado, envolvendo o sítio eletrônico WikiLeaks, a rede mundial de computadores tornou-se uma ferramenta poderosa de disseminação da informação e às instituições arquivísticas públicas caberia estender e aprofundar o seu uso. É certo, porém, que a grande plasticidade dos documentos digitais e a facilidade com que podem ser modificados, mutilados e distorcidos trazem preocupações adicionais quanto aos cuidados que devem cercar sua divulgação naquela gigantesca rede eletrônica de comunicação e informação. A natureza dos vínculos das instituições arquivísticas públicas com a documentação governamental dá a elas a vantagem de poder mais nitidamente chancelar a autenticidade das informações fornecidas, pois devem elas conhecer, em princípio, a trajetória de geração, tramitação, avaliação, guarda e disponibilização dos próprios documentos.

Conciliar governança e transparência, bem como o exercício de direitos que, em uma sociedade democrática, muito frequentemente entram em choque (como, no caso dos arquivos, o direito à informação e o direito à inviolabilidade da intimidade, da vida 
privada, da honra e da imagem), é tarefa complexa que põe em relevo o lugar das instituições arquivísticas públicas e seus conjuntos documentais. Cabe a estas instituições buscar respostas à altura dos desafios e aos cidadãos, exigi-las.

\section{Referências}

ALBERCH FUGUERAS, R.; CRUZ MUNDET, J.R. ¡Archive-se! - los documentos del poder, el poder de los documentos. Madrid: Alianza Editorial, 1999.

ASSANGE, J. et al. Cypherpunks: liberdade e o futuro da internet. São Paulo: Boitempo, 2013.

BLOCH, M. Apologia da história ou O ofício de historiador. Rio de Janeiro: Jorge Zahar, 2002.

BOOMS, H. La constitution du patrimoine archivistique: l'archivage comme activité sociale et politique. Archives, v. 35, n.1-2, 2003-2004, p.19-28. Disponível em: <http://www.archivistes.qc.ca/revuearchives/vol35_1_2/35-1-2-booms.pdf> Acesso em: 16 abr. 2013.

BOOMS, H. Ordre social et constitution du patrimoine archivistique: à propos de l'évaluation des sources d'archives. Archives, v. 33, n.3-4, 2001-2002, p.7-44. Disponível em: <http://www.archivistes.qc.ca/revuearchives/vol33_3-4/33-3-4-booms.pdf>. Acesso em: 16 abr. 2013.

CAIRE-JABINET, M.-P. Introdução à historiografia. Bauru (SP): EDUSC, 2003.

CAMARGO, A. M. de A. Sobre o valor histórico dos documentos. Arquivo Rio Claro. Rio Claro (SP): Arquivo do Município de Rio Claro, n.1, p.11-17, 2003.

CAMARGO, A. M. de A. Os arquivos e o acesso à verdade. In: SANTOS, C.M., TELES, E., TELES, J.de A. Desarquivando a ditadura: Memória e Justiça no Brasil. São Paulo: Hucitec, 2009. v.2, p.424-443.

CAMPANHOLE, A., CAMPANHOLE, H. L. (orgs.). Constituições do Brasil. 11 ed. São Paulo: Atlas, 1994.

CARBONELL, C.-O. La historiografia. México: Fondo de Cultura Económica, 1986. 
COMBE, S. Archives interdites: les peurs françaises à l'Histoire contemporaine. Paris: Albin Michel, 1994.

COOK, T. Archival appraisal and collection: issues, challenges, new approaches [Special Lecture Series, University of Maryland and NARA Staff, 21-22 April 1999]. Disponível em: <http://www.mybestdocs.com/cookt-nara-990421-2.htm>. Acesso em: 12 abr.2013.

COOK, T. Arquivos pessoais e arquivos institucionais: para um entendimento arquivístico comum da formação da memória em um mundo pós-moderno. Estudos históricos, Rio de Janeiro: FGV, v.11, n.21, p.129-149, 1998.

COUTURE, C. L'évaluation des archives: état de la question. Archives, v. 28, n.1, 1996-1997, p.3-31. Disponível em: <http://www.archivistes.qc.ca/revuearchives/vol28_1/28-1couture.pdf>. Acesso em: 13 abr. 2013.

DELMAS, B. La société sans mémoire: propos dissidents sur la politique des archives en France. Paris: Bourin, 2006.

DUCHEIN, M. Les obstacles à l'accés, à l'utilisation et au transfert de l'information contenue dans les archives: une étude RAMP. Paris: UNESCO, 1983.

FINDLAY, C. People, records and power: what archives can learn from WikiLeaks, Archives and Manuscripts. Sydney: Australian Society of Archivists, v.41, n.1, p.7-22, 2013. Disponível em: <http://dx.doi.org/10.1080/01576895.2013.779926 >. Acesso em 18 abr. 2013.

GINZBURG, C. Relações de força: história, retórica, prova. São Paulo: Companhia das Letras, 2002a.

GINZBURG, C. Sinais: raízes de um paradigma indiciário. In: _..Mitos, emblemas, sinais: morfologia e história. 2 ed. São Paulo: Companhia das Letras, 2002b.

GONÇALVES, J. Arquivos no presente: o lugar da História. Cadernos do CEOM, Chapecó: Centro de Memória do Oeste de Santa Catarina, n.22, p.75-96, dez.2005.

HARTOG, F. O tempo desorientado - tempo e história: "Como escrever a história da França?”. Anos 90. Porto Alegre: UFRGS, n.7, p.7-28, jul.1997.

HARTOG, F. Regimes de historicidade: presentismo e experiências do tempo. Belo Horizonte: Autêntica, 2013.

JARDIM, J. M. Transparência e opacidade do Estado no Brasil: usos e desusos da informação governamental. Niterói (RJ): Editora da UFF, 1999. 
LE GOFF, J. História e memória. São Paulo: Ed. da Unicamp, 1996.

LAMBERT, P., HARRISON, R., JONES, Aled. Metodologia - história científica e o problema da objetividade. In: LAMBERT, P., SCHOFIELD, P. (orgs.). História - introdução ao ensino e à prática. Porto Alegre: Penso, 2011. p.43-55.

LODOLINI, E. Archivística: princípios y problemas. Madrid: ANABAD, 1993.

MENNE-HARITZ, A. Appraisal or documentation: can we appraise archives by selecting content? The American Archivist. Chicago: Society of American Archivists, v.57, p.528-542, 1994.

REIS, J. C. A história, entre a filosofia e a ciência. São Paulo: Ática, 1999.

ROUSSO, H. O arquivo ou o indício de uma falta. Estudos históricos. Rio de Janeiro: FGV, v.9, n.17, 1996, p.85-91.

SAMUELS, H. W. Who controls the past? The American Archivist. Chicago: Society of American Archivists, v.49, n.2, p. 109-124, Spring 1986. Disponível em: <http://archivists.metapress.com/content/t76m2130txw40746/fulltext.pdf>. Acesso em: 18 abr. 2013.

SCHWARTZ, J. M.; COOK, T. Arquivos, documentos e poder: a construção da memória moderna. Registro. Indaiatuba (SP): Arquivo Municipal de Indaiatuba, n.3, p.18-33, jul.2004.

SILVA, A. M. da, et al. Arquivística - teoria e prática de uma ciência da informação. Porto: Afrontamento, 1999. v.1.

TESSITORE, V. Os Registros de Terras de São Paulo - inventário analítico. Revista Brasileira de História, São Paulo: ANPUH, v.6, n.12, p.187-196, mar./ago.1986.

VEYNE, P. Acreditaram os gregos nos seus mitos? [Lisboa]: Edições 70, 1987.

VIANA, N. O WikiLeaks e as batalhas digitais de Julian Assange. In: ASSANGE, J. et al. Cypherpunks: liberdade e o futuro da internet. São Paulo: Boitempo, 2013. p.9-18.

WEICHERT, M. A. Arquivos secretos e direito à verdade. In: SANTOS, C.M., TELES, E., TELES, J.de A. Desarquivando a ditadura: Memória e Justiça no Brasil. São Paulo: Hucitec, 2009. v.2, p.406-423. 
Recebido em: 02/12/2012 Aprovado em: 01/04/2013

Universidade do Estado de Santa Catarina - UDESC Programa de Pós-Graduação em História - PPGH Revista Tempo e Argumento Volume 05 - Número 09 - Ano 2013 tempoeargumento@gmail.com 